\title{
Strategies for the optimization of binomial energy saving landscape integration in road tunnels
}

\author{
J. C. López ${ }^{1,2}$, A. L. Grindlay ${ }^{2}$, M. Carpio ${ }^{3}$ \& A. Peña-García ${ }^{4}$ \\ ${ }^{l}$ CEMOSA Engineering and Control, Spain \\ ${ }^{2}$ Department of Urban and Regional Planning ETSICCP, \\ University of Granada, Spain \\ ${ }^{3}$ Department of Building Construction, University of Granada, Spain \\ ${ }^{4}$ Department of Civil Engineering, ETSICCP, \\ University of Granada, Spain
}

\begin{abstract}
The treatment of the zones above the entrance portal to road tunnels (plant cultivation, structures, etc.) is a topic of major interest due to the far-reaching implications from the perspectives of landscape integration, energy savings in the electric lighting and, definitively, its environmental sustainability. This work analyzes these perspectives with special attention to the optimization of the binomial "landscape integration-energy savings" and analyzes some proposals from an applied point of view; that is, considering direct action on real road tunnels. The huge energy consumption due to the electrical lighting of long road tunnels and its financial and environmental impact make this topic one of the priorities of tunneling and lighting technology. In fact, this impact does not concern only energy consumption, but also the consumption of electrical materials (the more lighting that is installed, the higher the consumption), the recyclability of these materials, etc. Although the treatment of the tunnel environment and the introduction of vegetation of the appropriate species can decrease such consumption, the integration of this species with the landscape is a very important topic frequently ignored. In this work, both aspects are optimized. Keywords: energy savings, road tunnels, electrical lighting, tunnel forestation.
\end{abstract}




\section{Introduction}

One of the critical aspects in the construction of road tunnels and their subsequent maintenance is the environmental and landscape integration. This importance concerns the landscape, but also the operation and functionality of the tunnel itself, for example in the matter of energy demands for the electrical lighting.

However, the landscape integration of vegetation (meadow and so on) is not an easy task. Specific rules cannot be given on how these transitions should be, nor how the environment should be resolved in what we might call the "frontier of the tunnel" (Estany i Serra and Esteyco [1]) given that it concerns a very particular design decision, but dependent on functional and structural necessities, on orography, the environment and the landscape, socio-environmental conditions, the construction process, the availability of space and traffic diversions, etc...

The zone above and around the so-called portal gate, is, perhaps, the most identifiable area of the tunnel, that which brings it visibility and identification. It is the area that can be appreciated from a wide perspective on approaching from the exterior and therefore that which lends itself to an aesthetic evaluation of its own configuration and as it is the transition element between the tunnel and the environment, in its final aim to integrate itself in some way with the landscape. Because of its elevated visibility, the satisfactory resolution of these frontier environs is the reflection of the integration not only of the structure itself but also, by extension, of the whole design of a route.

According to Estany i Serra and Esteyco [1] there is a basic rule that should be addressed in all cases: the integration of the tunnel mouth into the orography that contains it and into the landscape that frames it.

This concept of integration in itself is very wide and difficult to realise, it could be defined as the maximum effort to be made by professionals of different disciplines: geologists, biologists, engineers, landscape architects ... to minimize the effect of this new scar on the landscape. In this sense, the introduction of plant species is considered a highly relevant solution, given its impact both on the landscape and the energy consumption itself of the tunnels, as we shall see in this paper.

One of the problems in a road tunnel project is the lighting design. Although it is not a complicated task for night-time conditions, it becomes more complicated for daytime conditions [2,3] because the time needed for visual adaptation from a daylight environment to the darkness of a tunnel is longer during daytime than in night-time conditions. In particular, the luminance in the first part of the threshold zone, $L_{t h}$, is the part of the tunnel with the highest energy consumption [4].

For the design of a tunnel lighting installation, engineers need to know the highest value of the luminance $\left(\mathrm{cd} / \mathrm{m}^{2}\right.$-candelas per square meter-). There are several approximation methods to estimate the luminance in the access to tunnels. In this work the so called $L_{20}$ method has been used according to CIE Publ. 88 [4]. 
The $L_{20}$ value is the luminance in the $20^{\circ}$ conical field of view defined at a distance equal to the safety distance (SD) as defined in CIE Publ. 88 [4] from the tunnel entrance as shown in Figure 1. According to this CIE standard, the value of $L_{20}$ is obtained from a sketch of the tunnel-entrance surroundings as:

$$
L_{20} \approx \gamma L_{S}+\rho L_{R}+m L_{M}+b L_{B}
$$

In equation (1) $\mathrm{L}_{S}, \mathrm{~L}_{\mathrm{R}}, \mathrm{L}_{\mathrm{M}}$ and $\mathrm{L}_{\mathrm{B}}$ are the average luminances of sky, road, surrounding meadow and surrounding buildings, respectively, whereas, as shown in Figure 1, $\gamma, \rho, m$ and $b$ are the respective percentages of sky, road surrounding meadow and buildings (concrete zones are included here) in the $20^{\circ}$ cone. These coefficients obviously fulfil the relationship $\gamma+\rho+m+b=1$.

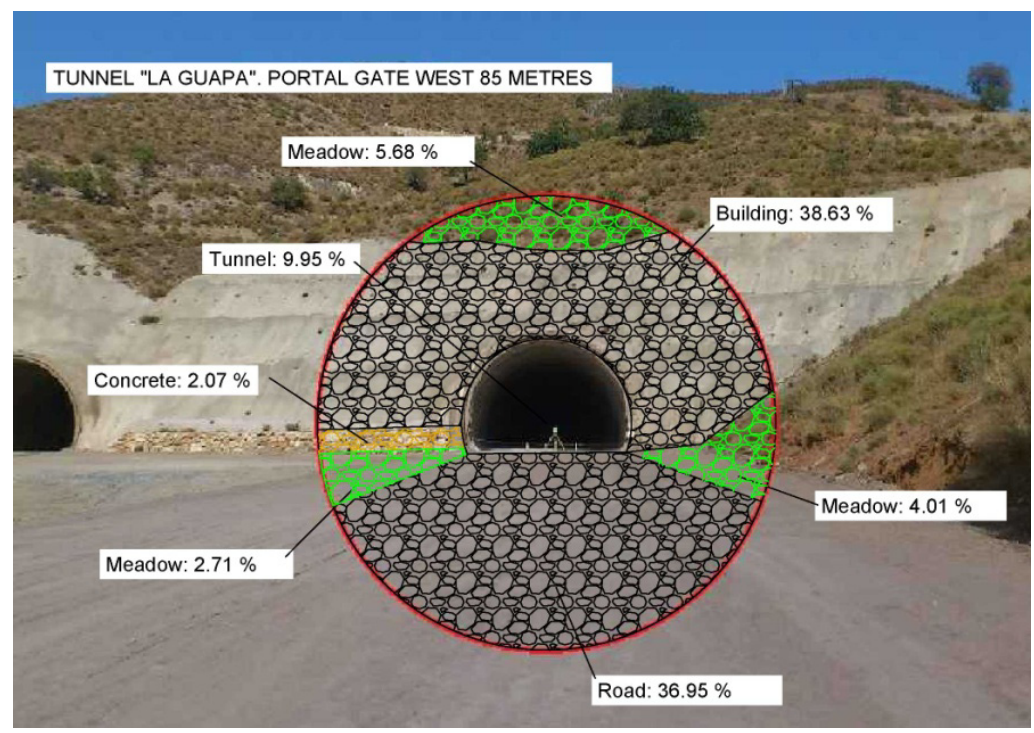

Figure 1: Road tunnel parallel to the Mediterranean coast in the southeast of Spain.

Thus, equation (1) gives the $L_{20}$ value at the tunnel entrance. Given that the values of the relevant luminances strongly vary depending on the season of the year, the orientation of the tunnel, the atmospheric conditions and other circumstances, the standard CIE Publ. 88 [4] provides average values that help us to calculate the $L_{20}$ according to equation (1).

A careful look at Table 1 shows that the more extensive the zone with meadow and vegetable species, the lower the contribution to $\mathrm{L}_{20}$. For example, the cultivation of the built zone, would make the contribution from 8,6 or $4 \mathrm{kcd} / \mathrm{m}^{2}$ to only $2 \mathrm{kcd} / \mathrm{m}^{2}$. 
In summary, according to the arguments above, minimizing the $\mathrm{L}_{20}$, which also means a decrease in $\mathrm{L}_{\mathrm{th}}$, because they are proportional, the requirements for the electrical lighting of the tunnel will be lower, thus achieving remarkable energy savings. In this sense, many different philosophies have been studied in recent years such as tension structures [5], pergolas [6] and light-pipes [7]. These ways to save energy deal with the use of sunlight and thus decrease the weight of

Table 1: Contribution to L20 of the different sections of the $20^{\circ}$ cone according to CIE Publ. 88 [4].

\begin{tabular}{|c|c|c|c|c|c|c|}
\hline \multirow{2}{*}{$\begin{array}{c}\text { Driving } \\
\text { direction } \\
\text { (North Hem.) }\end{array}$} & \multirow{2}{*}{$\begin{array}{c}\mathrm{L}_{\mathrm{c}} \\
\left(\mathrm{kcd} / \mathrm{m}^{2}\right)\end{array}$} & \multirow{2}{*}{$\begin{array}{c}\mathrm{L}_{\mathrm{r}} \\
\left(\mathrm{kcd} / \mathrm{m}^{2}\right)\end{array}$} & \multicolumn{4}{|c|}{$\mathrm{L}_{\mathrm{e}}\left(\mathrm{kcd} / \mathrm{m}^{2}\right)$} \\
\cline { 4 - 7 } & 8 & 8 & 3 & 8 & 15 & 2 \\
\hline $\mathrm{N}$ & 8 & 4 & 2 & 6 & $\begin{array}{c}10(\mathrm{~V}) \\
15(\mathrm{H})\end{array}$ & 2 \\
\hline $\mathrm{E}-\mathrm{W}$ & 12 & 5 & 1 & 4 & $\begin{array}{c}5(\mathrm{~V}) \\
15(\mathrm{H})\end{array}$ & 2 \\
\hline $\mathrm{S}$ & 16 & 5 & & & & \\
\hline
\end{tabular}

electrical lighting. However, not very much has been done in order to decrease directly the requirements for the electrical lighting itself.

In this work, a strategy consisting of the cultivation of the portal gate of road tunnels is considered in order to decrease $\mathrm{L}_{20}$ according to the figures in Table 1 .

\section{Materials and methods}

Four climbing species are considered for their possible integration into the areas surrounding the entrance portals/ways of the tunnels by its characteristics: Hedera helix, Carpobrotus edulis, Jasminum nudiflorum and Macfadyena unguis-cati.

Next follows a brief summary of the main characteristics of these species.

\subsection{Common Ivy (Hedera helix)}

Common Ivy, or Hedera helix is a botanical species of ivy native to the humid forests of West, Central and Southern Europe, North Africa and Asia from India to Japan. It is a relict plant and one of the few survivors in Europe of the laurel forest of the tertiary era. It is believed that its easy dispersion, affected by birds, helped it to colonize large areas from which it had disappeared during the glaciations.

\subsubsection{Characteristics and habitat}

Amongst the main characteristics of this species and its habitat, we may include the following:

- Its leaves are evergreen, resistant and tough, of a coriaceous nature. The colour is bright green and between $5-10 \mathrm{~cm}$ in diameter. There are two types of leaf on the same plant, those of non-flowering branches with lobed leaves and those lacking lobes on the flowering branches. 
- $\quad$ The flowers are small and green, the fruit is a pea-sized poisonous black berry.

- It is a climber, non-parasitic, fast-growing, reaching up to 50 metres in length, it can last longer than the tree over which it climbs.

- $\quad$ Temperatures between $10^{\circ}$ and $20^{\circ} \mathrm{C}$, although good cold resistance.

- $\quad$ Best suited to humid conditions.

- They grow more in shade, but once developed they need more direct sunlight.

- Thrive in fertilized, well-drained alkaline soils, tolerating various substrates, but the most suitable are those between ph 6 and 7 .
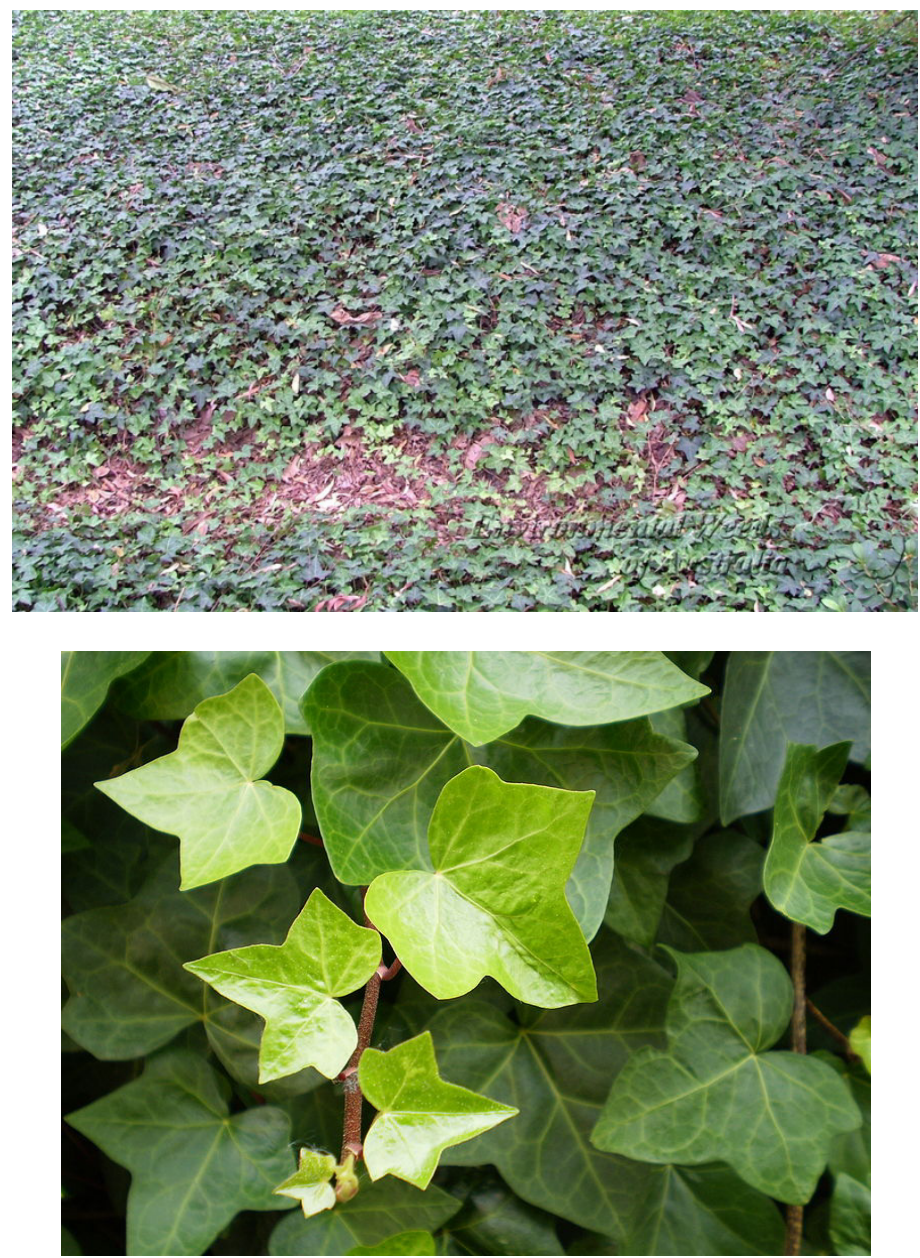

Figure 2: Hedera helix. 


\subsection{Carpobrotus edulis}

Carpobrotus edulis is a species of plant from the Aizoaceae family. One of the reasons for its introduction was its use as a rectification method in public works to consolidate slopes and thus slow down erosion caused by run-off or desertification, however, today measures are taken to avoid affecting native flora.
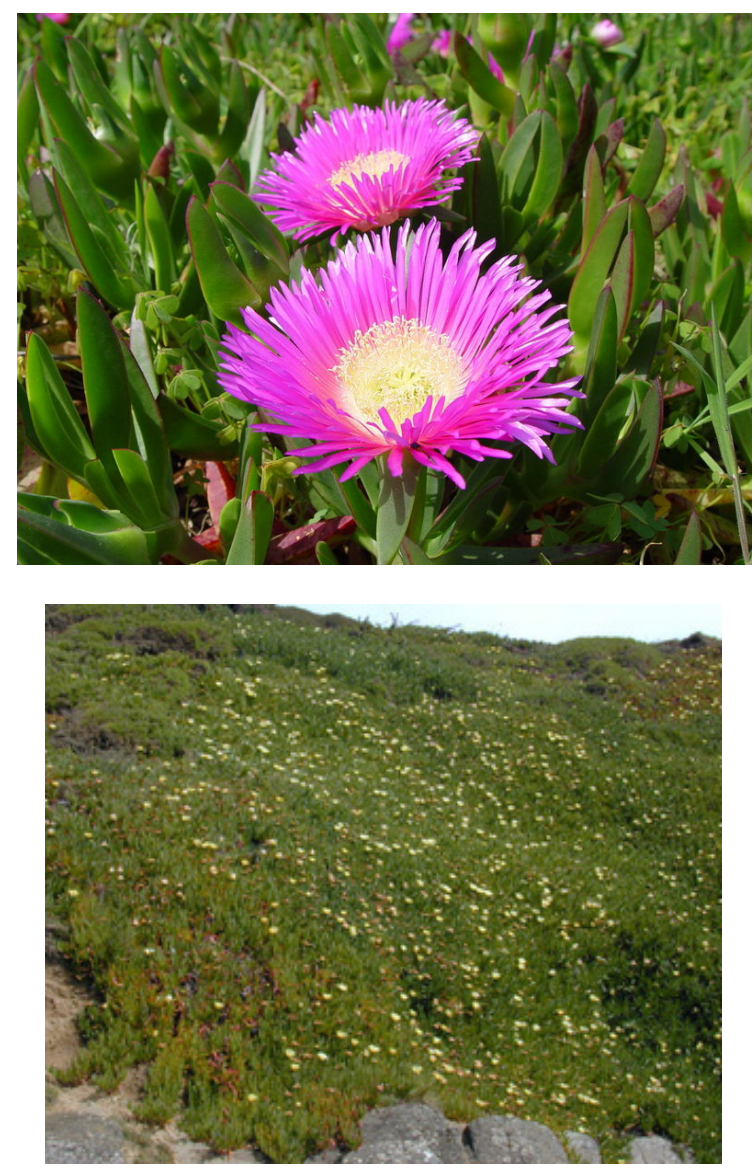

Figure 3: $\quad$ Carpobrotus edulis.

\subsubsection{Characteristics and habitat}

Amongst the main characteristics of this species and its habitat, we may include the following:

- $\quad$ Trailing and succulent appearance; with a tendency to cover large areas

- $\quad$ Forming dense carpets, the stem length can reach up to 2 metres, only around $15 \mathrm{~cm}$ from the ground.

- The leaves are evergreen, thick, bright green, sometimes purple at the extremities, and tapered with a waxy texture and a triangular cross-section, 
curved upwards, and the size of an index finger. In highly saline soils it can have a kind of saline crust that gives them a whitish surface.

- $\quad$ It is used as a ground cover or for covering very high walls, re-vegetating dry and steep slopes in coastal areas.

- $\quad$ Reproduces easily, in any season, planting about 7 to 10 cuttings per square metre.

- Tolerates edaphic characteristics very well which are unsuitable for other plants, such as salinity, so that it grows very well in poor, dry and inadequate soils. It is very drought resistant.

- It needs a lot of light and full sun. The minimum temperature of resistance is from $-6^{\circ} \mathrm{C}$.

- $\quad$ It really does not need any special care as, where many other plants would not survive, it thrives.

\subsection{Jasminum nudiflorum}

Jasminum nudiflorum or Jasmine is a kind of shrub from the Oleaceae family. It originates from southeastern Tibet.
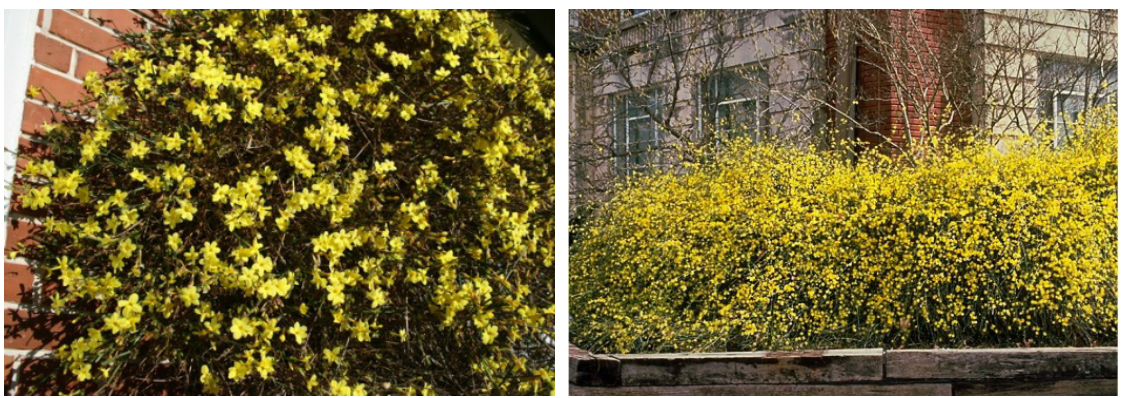

Figure 4: Jasminum nudiflorum.

\subsubsection{Characteristics and habitat}

- It is a deciduous climbing plant with a quadrangular stem. It has pinnate and opposed dark green, trifoliate and elliptical leaves.

- The solitary flowers have six pale yellow petals growing from the axillas, appearing on leafless branches in winter on the previous year's branches. Due to its early flowering, it is advisable to combine it with other climbers that provide their touch of colour at other times of the year, such as roses, clematis or honeysuckle. However, the density and beautiful deep green hue of its branches ensures a beautiful effect for the rest of the year.

- $\quad$ It can tolerate full sun, but it grows very well in partial shade, especially in regions with very hot summers. It resists frost very well.

- $\quad$ Irrigation needs to be regular, not copious, once or twice a week depending on whether the specimen is cultivated in open ground or in a pot. Do not water on frosty days. 
- $\quad$ Main uses are for covering walls, trellises or fences.

- It grows in a wide variety of soils, preferably fertilized, well-drained humus-rich soils, which can be limey.

- It grows without difficulty from cuttings of semi hard wood with leaves, taken at the end of summer and rooted in the greenhouse. Should be pruned in spring after flowering.

\subsection{Macfadyena unguis-cati}

Macfadyena unguis-cati, (Cat's Claw), is a type of flowering plant from the Bignoniaceae family. It is native to the dry tropical forest of Central and South America and the Caribbean, and is present throughout the world, except for Antarctica. It affects all layers of plants in forest ecosystems, for its rapid vertical and horizontal diffusion in contact with the herbaceous canopy.
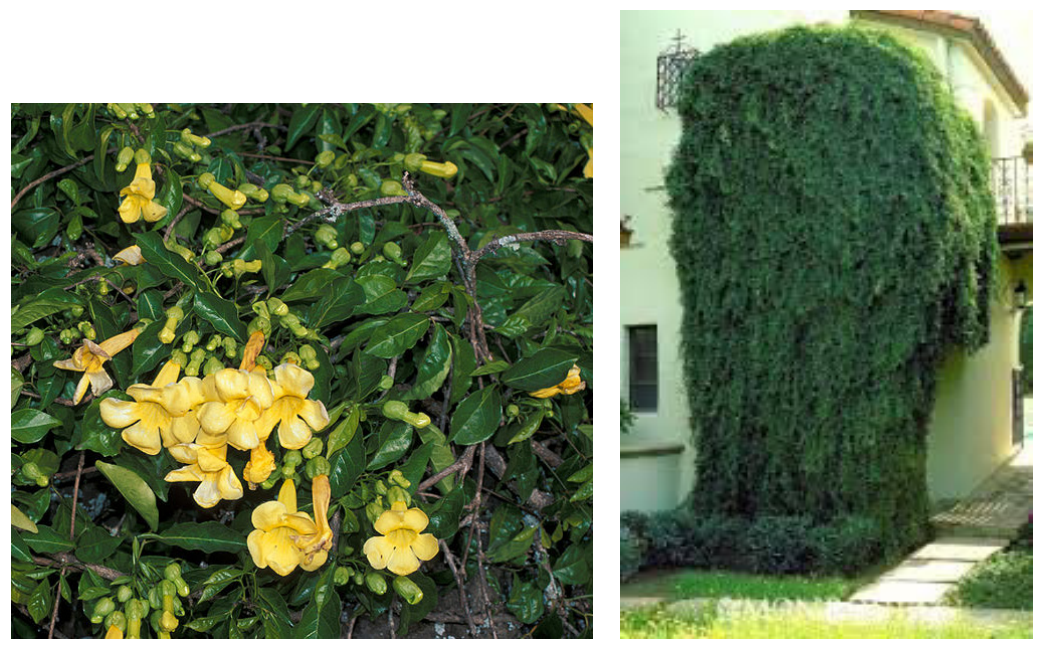

Figure 5: $\quad$ Macfadyena unguis-cati.

\subsubsection{Characteristics and habitat}

- It is a vigorous, woody plant with slender stems, being one of the few climbers that are truly adhesive, it clings to almost any surface using in addition to tendrils, small aerial roots on its branches. It has a high density of small, very bright semi-evergreen leaves. In protected, frost-free locations it persists, and where frosts usually occur, it is partially lost. Its green leaves are opposed, bi-foliate, ending in tendrils of 3 hooked branches. The leaves are 3 to $4 \mathrm{~cm}$ long. In spring or the beginning of summer it is covered in a blanket of yellow, trumpet-shaped flowers, although of short duration, which can grow singly or in groups of 2 or 3 . They have a diameter of 4 to $5 \mathrm{~cm}$. The fruits are smooth brown capsules. They are 20 to $40 \mathrm{~cm}$ in length by 1 to $1.5 \mathrm{~cm}$ diameter. 
- Other important characteristics are as follows:

- Be wary of its invasive character. It is voracious and difficult to eradicate, growing very quickly from seeds and also from cuttings.

- Its use is ideal for covering high walls with its abundant flowering, although only lasting a few weeks.

- It needs a lot of light and exposure to full sun, being well adapted to dry, hot climates, its large and fleshy roots allow it to survive drought and withstand temperatures down to $-8^{\circ} \mathrm{C}$.

- The soil should be well drained and cool with some organic matter. Watering should be regular but with moderate amounts of water, avoiding irrigation in winter, fertilizing with manure in spring and towards the end of summer.

- Prune lightly towards the end of winter to strengthen the plant and encourage side shoots.

\section{Impact on energy consumption in tunnels}

Given that the object of this paper is the integration of one of the species into a tunnel environment in the southeast of Spain, close to the Mediterranean Sea, with the aim of reducing energy consumption for its illumination, we should focus on the characteristics of these species best adapted to this habitat.

In view of the four climbing species studied for the potential integration over the entrance portals of the tunnels, Hedera helix, Carpobrotus edulis, Jasminum nudiflorum and Macfadyena unguis-cati, at first appraisal Hedera helix or Macfadyena unguis-cati seem most promising, taking into account that the location of these will be in a coastal zone and Mediterranean climate.

Macfadyena unguis-cati has abundant flowering though its invasive character involves special maintenance. However, its resistance to drought and its growth in soil of characteristics related to the Mediterranean climate is what leads us to consider it.

With Hedera helix, we have in its favour the need for light, its rapid growth, evergreen leaves (fundamental in its implementation in public road works), resistant and hardy, its climbing nature will help to cover larger areas around and above the tunnel, thereby improving the lighting parameters relevant to the aim of this paper, requiring little maintenance. The need for excessive moisture, frustrates our initial choice, being an indispensable quality, our coastal Mediterranean climate may be too dry to sustain it. However, as the orientation of the tunnels in the whole of the Mediterranean area is East-West, West-East, planting it in the northern area could reduce the necessary water requirements in an early stage of its development, solar light being indispensable after this.

Beyond these hydrological and agricultural considerations, according to the requirements of the Introduction, the chosen species must be compatible with the integration into the landscape.

Therefore, Hedera helix seems a good choice, in our aim of reducing the energy consumption in the artificial illumination of the tunnels. 


\section{Conclusions}

Several conclusions can be taken from the considerations in the paragraphs above:

1. One of the most relevant topics when considering landscape integration of road tunnels is the choice of vegetation to cover the zones surrounding the portal gate.

2. Very high luminance levels are required in the first part of road tunnels, also called the threshold zone. This requirement arises from the remarkable lapse of time needed for the human eye to become adapted from bright to darker environments.

3. The only way to decrease these huge consumptions consists of the use of sunlight as a complement to electrical lighting or, as dealt with in this work, decreasing the $\mathrm{L}_{20}$ at the portal gate of road tunnels.

4. An effective measure to decrease this $\mathrm{L}_{20}$ consists on the replacement of concrete or built surroundings of the portal gate by cultivated zones.

5. Among several candidates for the models tunnels in the south-east of Spain, very close to the Mediterranean Sea, the Hedera helix seems to be the most suitable candidate, due to its optimal adaptation to the climate and hydrological conditions of this zone.

6. Future research will be focused on determining the reflective coefficients of all these species and this research will be extended to other climates where other species could be more suitable.

\section{References}

[1] Estany i Serra, A., Esteyco, S.A.P., La frontera del túnel. V Simposio de Túneles de Carretera: Seguridad para los túneles del siglo XXI. Bilbao, 2010.

[2] Adrian, W., Investigations on the required luminance in tunnel entrances, Lighting Res. Technol. 14, pp. 151-159, 1982.

[3] Schreuder, D.A., Tunnel entrance lighting: a comparison of recommended practice. Lighting Research Technology 3, pp. 274-278, 1971.

[4] Commission Internationale de l'Éclairage, CIE., Guide for the lighting of road tunnels and underpasses, CIE Publ. 88, Vienna, 2004.

[5] Gil-Martín, L.M., Peña-García, A., Hernández-Montes, E., \& Espín-Estrella, A., Tension structures: A way towards sustainable lighting in road tunnels. Tunnelling and Underground Space Technology 26, pp. 223-227, 2011.

[6] Peña-García, A., Gil-Martín, L.M., Study of pergolas for energy savings in road tunnels. Comparison with tension structures. Tunnelling and Underground Space Technology, 35, pp. 172-177, 2013.

[7] Gil-Martín, L.M., Peña-García, A., Jiménez, A. \& Hernández-Montes, E., Study of Light-pipes for the use of sunlight in road tunnels: from a scale model to real tunnels, Tunnelling and Underground Space Technology, 41, pp. 82-87, 2014. 